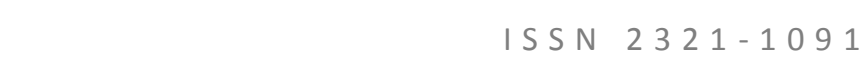

\title{
A Comparative Analysis of Elitist and Public Opinion Evaluation of National Health Insurance Policy Performance

$$
\begin{gathered}
\text { Liu I-chun', Chen Chii-ching } \\
\text { 'Yuan Ze University, Taiwan } \\
\text { chun0820@saturn.yzu.edu.tw } \\
{ }^{2} \text { Kainan University, Taiwan } \\
\text { ccchen@mail.knu.edu.tw }
\end{gathered}
$$

\begin{abstract}
This study discusses evaluation of National Health Insurance policy, using the policy Delphi method to obtain elite opinion on evaluation indicators of the policy and a telephone survey to collect general public opinion. Results indicated that the elite and the general public share a consensus on policy performance. The findings suggest that evaluations of $\mathrm{NHI}$ policy that incorporate elite and general public assessments may be preferable to evaluations based on assessments from just one sector of the population. Moreover, performance assessment should integrate the opinions of different representative sections of the population, as well as professional and democratic principles of decision-making. The study also provides evidence that public opinion and elite evaluation are correlated and shows considerable consistency in the evaluation of $\mathrm{NHI}$ policy regardless of the policy knowledge of the evaluators.
\end{abstract}

\section{Indexing terms/Keywords}

Performance assessment, National Health Insurance policy, public opinion, Delphi method.

\section{Academic Discipline And Sub-Disciplines}

Public policy analysis

\section{SUBJECT CLASSIFICATION}

Policy evaluation

\section{TYPE (METHOD/APPROACH)}

\author{
Survey; Delphi method
}

\section{INTRODUCTION}

Groups with different preferences assess the performance of National Health Insurance (NHI) policies from various perspectives. For example, the public advocates policies those promote fairness, whereas the elite believe that policies should increase the efficiency of medical resource utilization. These two groups, which have different levels of interest in and knowledge of $\mathrm{NHI}$ policies, may have inconsistent views; however, their opinions are given the same degree of attention when a decision-making system is designed.

In the field of health policy research, some researchers have collected data on the elitist and public opinions from different periods; however, most researchers have collected data from a single research subject, and therefore, comparative analyses of elitist and public opinions have been unreliable. Because preferences and perspectives vary, yet remain critical to the decision-making process regarding health policies, this paper describes a comparative analysis of the elitist and public opinions regarding $\mathrm{NHI}$ policy performance evaluation.

The purpose of this article is to examine the difference between elitist and public opinions by using NHI policy evaluation as a case study. Thus, the policy Delphi method was used to collect elitist opinions about the NHI policy performance and a questionnaire for measuring public opinion was created according to the elitist opinions. The researcher then conducted a telephone survey to determine public opinion. Finally, both the elitist and public opinions were compared.

\section{Case Introduction}

This section briefly describes the major characteristics of Taiwan's NHI policy. The NHI system was introduced in Taiwan in 1995 and is characterized by accessibility, comprehensive population coverage, short waiting times, low costs, adequate care for disadvantaged groups, and a high level of public satisfaction (Cheng \& Chu, 2007; Wu, Majeed, \& Kuo, 2010). By 2013 , approximately $100 \%$ of Taiwan's residents had health insurance coverage. The policy, which is widely supported and consistently receives high public satisfaction rates, has attracted considerable international attention. In 2000, The Economist, the Intelligence Unit of which evaluated the health conditions in 27 principal countries according to 13 health indices, ranked Taiwan as the second healthiest country in the world. Paul Krugman, the 2008 winner of the Nobel Prize for Economics, lauded Taiwan's NHI policy, saying, "Taiwan, which moved 10 years ago from a U.S.-style system to a Canadian-style single-payer system, offers an object lesson in the economic advantages of universal coverage." Although the system is far from perfect, its indicators of health status and consumer satisfaction are high; its expenditures, as a share of gross domestic product, are far lower than those in most developed countries; and patients have an extraordinary degree of choice among providers. TYPESET TEXT 


\section{Elitist Assessment of the National Health Insurance Policy}

The elaboration and selection of performance indicators are highly dependent on the conceptual framework that is adopted for evaluating the performance of health systems (Handler, Issel, \& Turnock, 2001). According to the Organization for Economic Co-operation and Development (OECD), which is comprised of experts that can represent the elite, there are four standards in the health systems that can influence policy performance: health system inputs, health system design, monitoring mechanisms, and health system improvements, which include the perspectives of policy processes and outcomes (OECD, 2010a).

The first standard, health system inputs, refers to the availability and accessibility of medical resources that are correlated with equity. Equity is perceived as a critical goal in health care (Cuyler \& Wagstaff, 1993; Gwatkin, 2001). The distance from people's homes to medical resources is a key determinant of access (Kreng \& Yang, 2011; Pauline, 2010). For example, Lu and Hsiao (2003) found that Taiwanese people have equal access to health care. Chen et al. (2007) obtained similar results and found an increased use of health services by estimating the extent to which the NHI policy reduces gaps in access. Recently, Kreng and Yang (2011) measured the horizontal equity of health care resource allocation according to Taiwan's NHI policy. They found that most resources were allocated in Northern Taiwan, resulting in geographic disparity caused by unbalanced health care resource allocation. Therefore, the sufficiency of hospital and physician resources, particularly for providing access to medical services for people in all areas, were included as health system input indicators in this study.

The second standard, health system design, determines the responsibilities of various stakeholders (including the government and providers) in delivering services (OECD, 2010a). The NHI policy emphasizes universal coverage as the fundamental objective (World Health Organization, 2010). Kreng and Yang (2011) and the OECD (2010a) have found a similarly high level of concern regarding the equity of insurance premiums. When analyzing the universal health care systems of 13 countries, Da Costa et al. (2008) determined the principles that must be considered when establishing a national health insurance program. The 13 countries (including Taiwan) have high levels of formal employment and provide universal coverage and a comprehensive benefit package. In the present study, the efficacy of health system design included the coverage rate, universally affordable insurance premiums, equity of insurance premiums, and a comprehensive service package.

The third standard, monitoring mechanisms, is a prominent feature in ensuring that the provision process involves accountability and transparency (Lloyd \& Wait, 2006). Maluka et al. (2010) examined the process, actors, and contextual factors shaping the priority-setting processes of health insurance. Recently, various international studies focused on this topic. Lee et al. (2009) found that the policy accountability attitude toward the NHI program in South Korea was the most vital factor in determining public satisfaction. Improving public recognition of policy values is crucial to increase the public satisfaction with a national health insurance program. Lu and Chiang (2011) indicated that public involvement is a fundamental component of improving accountability. The performance of a monitoring system in this study included transparent decision-making that involves public satisfaction and participation.

The fourth standard, health system improvement, addresses the fact that, in practice, many OECD countries have launched policy reforms to reduce medical spending and alleviate pressure on public finances that stems from health care demands and aging populations (OECD, 2010c). Hsiao (2006) used a cost-effectiveness analysis to evaluate system performance and suggested that performance should include efficiency and effectiveness. Lee et al. (2010) found that the $\mathrm{NHI}$ performance was associated with a reduced number of deaths attributable to health care, particularly among the age groups least likely to have been insured previously. In the present study, the performance perspectives of health outcomes included efficiency and effectiveness. The policy performance perspectives were derived from the OECD framework of health system performance to design a questionnaire that could be used to evaluate the elitist opinion.

\section{Public Opinion and the National Health Insurance Policy}

Although social scientists have debated the relevance of public opinion on policies, a growing body of work suggests that public opinion on policy-related topics is critical (Schlesinger \& Lee, 1993). Additionally, because nearly all citizens have personally experienced the system, they are more likely to form coherent opinions. The researchers also noted that health care has remained a key concern for voters even though health reform has been less visible as a policy premise (Soroka, 2011). Koch (1998) asserted that the ideas and arguments of political elites can considerably influence shaping public opinion on matters such as health care. In such a situation, people may be particularly susceptible to elites who aim to sway opinions. Therefore, determining the structure of public attitudes toward health care policies is critical for ascertaining how (or the extent to which) representative democracy works and understanding future (as well as past) changes in health care policies (Soroka, Maioni, \& Martin, 2012). Some studies investigate how social inequities in health care are experienced by people in different sections of society. Additionally, some empirical studies have found that public recognition and support are the basis for efficient operation and reform of national health insurance policies. Although the public anticipates that the healthcare system will serve them favorably, public views regarding the ongoing efforts to improve the coordination, quality, and effectiveness of health care may afford warnings for policy makers (Robert Wood Johnson Foundation, 2009).

\section{Methods}

The goal of this research was to compare the difference between the elitist and public opinions. This study adopted the policy Delphi method for collecting and collating the opinions of the elite regarding NHI policy evaluation. The survey questions for the elitist group were designed according to the aforementioned results and practices related to $\mathrm{NHI}$ policies. A total of 50 experts, including administrative and academic elites, participated in the survey after undergoing a pretest; 
the unanimous opinion of the elitist group obtained using the policy Delphi method was used as the basis for designing the questionnaire for the public opinion survey. The questionnaire respondents comprised adults older than 20 years who lived in Taiwan. A telephonic survey in which 1,103 participants were interviewed was conducted. At the 95\% confidence interval, the maximal error was $\pm 3.0 \%$, and no significant difference was observed between the distribution of samples in terms of regions and participants

\section{Results}

An independent sample t test was conducted to examine the difference between the public and elitist opinions. Because of a large gap between the number of elitist and public participants in the survey (50 and 1,103, respectively, in the two rounds), weights were added to the opinion scores based on the sample size to avoid errors in the comparison. Confounding factors such as age, sex, and educational attainment were controlled for. The proportion of the elitist and public participants was obtained, and a weight of 0.95 was added to the public opinion mean score based on the weight of the elitist opinion score. The total scores of the two groups were then averaged and used as the basis for comparison.

First, after the scores were weighted, the highest mean score was regarded as the central tendency of opinions. The results showed that the highest level of consensus achieved by the elitist group was in the "coverage rate" category, and the lowest was in "hospitals and physicians are sufficient." This revealed that the elitist participants focused on the overall $\mathrm{NHI}$ performance. Conversely, the highest level of consensus achieved by the public group was for the categories "decisions regarding $\mathrm{NHI}$ issues are disclosed to the public" and "provides comprehensive medical services," and the lowest was for "hospitals and physicians are sufficient."

Second, the indicators with the mean scores of the elitist and public opinions differing by less than 0.5 included "provides comprehensive medical services," "enhances medical services for people in rural areas," "hospitals and physicians are sufficient," "public satisfaction toward the NHI," "people's health is guaranteed at the lowest cost," "the NHI effectively improves people's health," and "decisions regarding NHI issues are disclosed to the public."

In other words, the participants in both the elitist and public groups considered the following items to be suitable $\mathrm{NH}$ performance indicators: benefits offered through $\mathrm{NHI}$ services, adequacy of medical resources, system design accountability, disclosure of decision information, overall efficiency of $\mathrm{NHI}$ resource usage, and the degree to which policy goals are achieved. This result is consistent with the crucial aspects of the current NHI policies. The respondents in the public group considered disclosure of governmental discussions related to $\mathrm{NHI}$ policies to be extremely crucial, followed by the integrity of the $\mathrm{NHI}$ coverage and the efficiency of medical resource usage.

Third, the indicators with the mean score of the elite and public opinions differing by less than 0.5 included "insurance premium based on economic status," "accessibility to health care services in different areas," and "insurance premiums are established considering the financial capacity of each family." In contrast to the public group, the elitist group regarded these three indicators as being the most critical to $\mathrm{NHI}$ policies.

Finally, the universal coverage exhibited a difference of 0.9 in the mean scores of the elitist and public opinions. In other words, the respondents in the elitist group favored adopting this item as an evaluation indicator, whereas those in the public group did not.

Table 1: Levels of importance assigned to the performance of the NHI policy by the public and the elite (\% of respondents)

\begin{tabular}{l|l|c|c|c|c|c}
\hline & & $(5)$ & $(4)$ & $(3)$ & $(2)$ & $(1)$ \\
\hline \multirow{2}{*}{\begin{tabular}{l} 
Coverage rate \\
\cline { 2 - 7 }
\end{tabular}} & The public & 9.8 & 60.4 & 10.4 & 12.0 & 0.3 \\
\cline { 2 - 7 } & The elite & 68.0 & 28.0 & 4.0 & 0.0 & 0.0 \\
\hline \hline $\begin{array}{l}\text { Insurance premium } \\
\text { based on one's } \\
\text { economic status }\end{array}$ & The public & 9.2 & 64.0 & 9.2 & 10.0 & 0.3 \\
\cline { 2 - 7 } & The elite & 64.0 & 20.0 & 16.0 & 0.0 & 0.0 \\
\hline \hline $\begin{array}{l}\text { Accessibility to health } \\
\text { care services in different } \\
\begin{array}{l}\text { areas } \\
\hline \hline\end{array}\end{array}$ & The public & 9.5 & 58.9 & 9.7 & 10.7 & 0.4 \\
\cline { 2 - 7 } $\begin{array}{l}\text { Provides comprehensive } \\
\text { medical services }\end{array}$ & The elite & 64.0 & 28.0 & 4.0 & 4.0 & 0.0 \\
\hline \hline $\begin{array}{l}\text { Enhances medical } \\
\text { services for people in } \\
\text { rural areas }\end{array}$ & The public & 11.6 & 70.4 & 5.6 & 5.1 & 0.3 \\
\hline \hline
\end{tabular}




\begin{tabular}{l|l|l|l|l|l|l}
\hline \hline \multirow{2}{*}{$\begin{array}{l}\text { Hospitals and physicians } \\
\text { are sufficient }\end{array}$} & The public & 9.2 & 64.4 & 8.1 & 9.0 & 0.2 \\
\cline { 2 - 7 } & The elite & 32.0 & 48.0 & 8.0 & 12.0 & 0.0 \\
\hline \hline $\begin{array}{l}\text { Insurance premium is set } \\
\begin{array}{l}\text { considering the financial } \\
\text { capacity of each family }\end{array}\end{array}$ & The public & 11.7 & 65.3 & 7.1 & 8.3 & 0.3 \\
\cline { 2 - 7 } & The elite & 36.0 & 48.0 & 8.0 & 0.0 & 0.0 \\
\hline \hline $\begin{array}{l}\text { Public satisfaction } \\
\text { toward NHI }\end{array}$ & The public & 10.2 & 65.9 & 10.1 & 7.3 & 0.3 \\
\cline { 2 - 7 } & The elite & 28.0 & 32.0 & 40.0 & 0.0 & 0.0 \\
\hline \hline $\begin{array}{l}\text { People's health is } \\
\text { guaranteed with the least } \\
\text { charge }\end{array}$ & The public & 12.9 & 69.5 & 6.4 & 5.2 & 0.4 \\
\cline { 2 - 7 } & The elite & 12.0 & 52.0 & 24.0 & 12.0 & 0.0 \\
\hline \hline \multirow{2}{*}{$\begin{array}{l}\text { NHI effectively improves } \\
\text { people's health }\end{array}$} & The public & 9.9 & 67.3 & 9.8 & 6.5 & 0.1 \\
\cline { 2 - 7 } & The elite & 28.0 & 60.0 & 4.0 & 8.0 & 0.0 \\
\hline \hline
\end{tabular}

*5-extremely important; 4-very importance; 3-neutral; 2-not very important; 1-not at all important

Table 2: The comparison of weight mean of the elite and the public opinions in $\mathrm{NHI}$ policy performance

\begin{tabular}{|c|c|c|c|}
\hline item & Dimensions of $\mathrm{NHI}$ policy performance & The elite & The public \\
\hline$\overline{1}$ & Coverage rate & 4.61 & 3.73 \\
\hline 2 & Insurance premium based on one's economic status & 4.39 & 3.78 \\
\hline 3 & Accessibility to health care services in different areas & 4.39 & 3.75 \\
\hline 4 & Provides comprehensive medical services & 3.76 & 3.95 \\
\hline 5 & Enhances medical services for people in rural areas & 4.33 & 3.94 \\
\hline 6 & Hospitals and physicians are sufficient & 3.44 & 3.81 \\
\hline 7 & $\begin{array}{l}\text { Insurance premium is set considering the financial capacity of } \\
\text { each family }\end{array}$ & 4.48 & 3.86 \\
\hline 8 & Public satisfaction toward $\mathrm{NHI}$ & 3.88 & 3.84 \\
\hline 9 & People's health is guaranteed with the least charge & 3.64 & 3.95 \\
\hline 10 & NHI effectively improves people's health & 3.80 & 3.86 \\
\hline 11 & Decisions of $\mathrm{NHI}$ issues are open to the public & 4.28 & 4.02 \\
\hline
\end{tabular}

*5-extremely important; 4-very importance; 3-neutral; 2-not very important; 1-not at all important

A t test was conducted on the weighted mean scores to examine whether the elitist and public opinions differed. The following two hypotheses were proposed:

$\mathrm{HO}$ : The mean scores of the public and elitist opinions toward $\mathrm{NHI}$ indicators exhibited no significant difference.

$\mathrm{H} 1$ : The mean scores of the public and elitist opinions toward $\mathrm{NHI}$ indicators differed significantly.

The independent sample t-test results showed that there were no significant differences between the public and elite groups for the following six performance indicators: efficacy, insurance integrity, remote resource adequacy, resource adequacy, satisfaction accountability, and information disclosure. However, the opinions of the participants in the two groups differed regarding service accessibility, efficiency, and financial equity. 


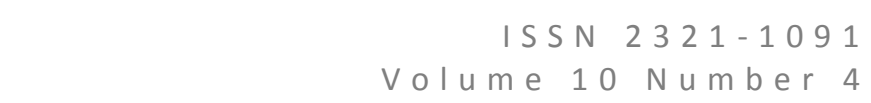

Journal of Social Sciences Research

The results are summarized as follows:

First, the respondents in the public and elitist groups agreed that "decisions regarding $\mathrm{NHI}$ issues are disclosed to the public" was a suitable indicator of policy performance. This implied that the reform of the second-generation NHI, particularly in aspects regarding government accountability, is appropriate and strongly supported by society.

Second, participants in the public and the elitist groups agreed that "accessibility to health care services in different areas," "the NHI effectively improves people's health," and "insurance premiums are established considering the financial capacity of each family" are suitable NHI performance evaluation indicators. The two groups exhibited a high level of consensus regarding "decisions regarding $\mathrm{NHI}$ issues are disclosed to the public," "public satisfaction toward the NHI," "enhances medical services for people in rural areas," and "provides comprehensive medical services." Thus, adopting these items as $\mathrm{NHI}$ indicators and using them as the basis for reform would receive public support.

Several indicators, such as NHI benefits and the disclosure of government discussions on NHI-related topics, were directly related to the $\mathrm{NHI}$ policy system design; however, the majority of the indicators that achieved consensus among the participants were relevant to medical service systems. These indicators included regional allocation of medical resources, public health enhancement, and medical care in remote areas. NHI policies enable people to access effective medical services; however, the core of medical care service remains associated with enhancing service value. Thus, the efficiency of the medical system cannot be ignored when evaluating NHI policies.

Third, the participants in the elitist group possessed professional knowledge and foresight, and thus tended to evaluate policy performance according to overall system design, whereas the participants in the public group typically expressed opinions according to personal experiences. Therefore, the majority of the participants in the elitist group regarded "coverage rate" and "accessibility to health care services in different areas" as adequate evaluation indicators, whereas the participants in the public group were concerned about "decisions regarding NHI issues are disclosed to the public" and "people's health is guaranteed at the lowest cost." Although the participants in the public and the elitist groups had inconsistent opinions toward efficacy and satisfaction accountability, the inconsistency was not salient. Therefore, substantial attention should be paid when analyzing the consistency in elitist and public opinion.

Finally, the participants in the public and elitist groups did not reach a consensus on "coverage rate." The participants in the elitist group believed that this indicator was crucial for achieving policy goals, whereas those in the public group indicated that including all citizens in the $\mathrm{NHI}$ is imperative for policy implementation, rather than for assessing $\mathrm{NHI}$ policy performance. In other words, although the participants in the public and elitist groups agreed about most indicators, those in the public group considered "coverage rate" to be an unsuitable indicator. This may be because the NHI implemented in Taiwan is mandatory for all citizens, prompting some people to view the policy as a requirement rather than as a method of enhancing policy effectiveness.

Table 3: Weighted average test results for public and elite opinions

\begin{tabular}{|c|c|c|c|}
\hline $\begin{array}{l}\text { Dimensions of NHI policy } \\
\text { performance }\end{array}$ & p-value & consistency /inconsistency & remark \\
\hline Coverage rate & 0.000 & inconsistency & $\begin{array}{l}\text { Agreement ratio: greater } \\
\text { consensus among elite than } \\
\text { among the public. } \\
\text { The same as unweighted } \\
\text { mean comparison result. }\end{array}$ \\
\hline $\begin{array}{l}\text { Insurance premium based on one's } \\
\text { economic status }\end{array}$ & 0.000 & inconsistency & $\begin{array}{l}\text { Agreement ratio: the elite is } \\
\text { more than the public } \\
\text { The same as unweighted } \\
\text { mean comparision result }\end{array}$ \\
\hline $\begin{array}{l}\text { Accessibility to health care services } \\
\text { in different areas }\end{array}$ & 0.006 & inconsistency & $\begin{array}{l}\text { Agreement ratio: the elite is } \\
\text { more than the public } \\
\text { The same as unweighted } \\
\text { mean comparision result }\end{array}$ \\
\hline $\begin{array}{l}\text { Provides comprehensive medical } \\
\text { services }\end{array}$ & 0.058 & consistency & \\
\hline $\begin{array}{l}\text { Enhances medical services for } \\
\text { people in rural areas }\end{array}$ & 0.069 & consistency & \\
\hline $\begin{array}{l}\text { Hospitals and physicians are } \\
\text { sufficient }\end{array}$ & 0.414 & consistency & \\
\hline $\begin{array}{l}\text { Insurance premium is set } \\
\text { considering the financial capacity of } \\
\text { each family }\end{array}$ & 0.002 & inconsistency & $\begin{array}{l}\text { Agreement ratio: the elite is } \\
\text { more than the public } \\
\text { The same as unweighted } \\
\text { mean comparision result }\end{array}$ \\
\hline
\end{tabular}




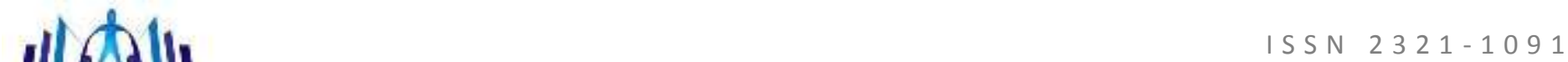

\begin{tabular}{l|l|l|l}
\hline Public satisfaction toward NHI & 0.037 & consistency & $\begin{array}{l}\text { If } \mathrm{P}<0.05 \text { then reject } \mathrm{H}_{0} \\
\text { inconsistency between the } \\
\text { public and the elite. } \\
\text { Agreement ratio: greater } \\
\text { consensus among elite than } \\
\text { among public. } \\
\text { The inconsistency is } \\
\text { different from the } \\
\text { unweighted mean } \\
\text { comparison result }\end{array}$ \\
\hline $\begin{array}{l}\text { People's health is guaranteed with } \\
\text { the least charge }\end{array}$ & 0.000 & inconsistency & $\begin{array}{l}\text { Agreement ratio: the public } \\
\text { is more than the elite } \\
\text { The same as unweighted } \\
\text { mean comparision result }\end{array}$ \\
\hline $\begin{array}{l}\text { NHI effectively improves people's } \\
\text { health }\end{array}$ & 0.025 & consistency & $\begin{array}{l}\text { If P<0.05 then reject } \mathrm{H}_{0} \\
\text { The inconsistency different } \\
\text { from unweighted mean } \\
\text { comparision result }\end{array}$ \\
\hline $\begin{array}{l}\text { Decisions of NHI issues are open to } \\
\text { the public }\end{array}$ & 0.062 & consistency & \\
\hline
\end{tabular}

\section{Policy Recommendations}

The results indicate that, in general, the participants in the elitist and public groups agree. The differences between the groups are informative and suggest that in the future, evaluations of NHI policies that incorporate assessments by both the elite and the general public may be preferable to evaluations based solely on professional evaluators or the general public. Several recommendations for NHI reform are proposed based on the NHI indicators.

First, decision makers can consider the policy indicators that were formulated through professional knowledge and democratic participation, such as insurance integrity, remote resource adequacy, resource adequacy, information disclosure, satisfaction accountability, and efficacy. These indicators represent multiple effects exerted by NHI policies. If the government can emphasize the effectiveness of the NHI program by using these indicators, social or media attention could be steered toward the effectiveness of implementation, rather than toward problems such as the financial loss of the $\mathrm{NHI}$.

Second, the participants perceived several indicators differently, including the $\mathrm{NHI}$ universality and other finance-related indicators such as premium payments and medical expenditures. Previous studies have revealed that the elite and the public perceive the economic burden caused by policy implementation differently because of distinct socioeconomic statuses; members of the public group were concerned about personal financial burden. Consequently, policy opinion disparity resulting from the structural factor of socioeconomic status cannot be resolved by merely strengthening people's knowledge to integrate opinions or resolve disputes. Thus, if insurance premium payments or partial payments are involved in the $\mathrm{NHI}$ reform agenda, it may become the focus of dispute, and thus, policy makers should endeavor to advocate and explain policy content.

Third, according to the statistical analyses, ambiguous results regarding consistency between the public and elitist opinions were obtained for several indicators, such as payment affordability, financial equity, service accessibility, and efficiency. Although this ambiguity indicates that diverse values regarding NHI policies exist in society, it also implies that decision-makers should eliminate factors that engender inconsistent opinions. For example, the government can educate people on the implications of the $\mathrm{NHI}$ implementation, steering opinions until everyone is in agreement or integrating opinions to form a majority opinion in society.

\section{Research Value and Limitations}

Previous studies have compared and analyzed the elitist and public opinions on policies; however, these studies were conducted in different periods, and the research questions posed were unclear. The present study is the first to design a questionnaire according to elitist opinions and then use it to determine public opinion. Furthermore, weighting was performed according to the number of participants to avoid comparison errors. Unlike previous studies that have analyzed a single sample group, this study assessed NHI policies by focusing on two sample groups. Moreover, during the survey, the questionnaire design enabled the participants to examine which aspects of NHI policies they favor. Thus, this study contributes by providing results that can be referred to when investigating other policies. However, even though this study constructed the $\mathrm{NHI}$ indicators according to the perspectives of two sample groups, it has several limitations.

This study compared the opinions of the elite with those of the public by utilizing the policy Delphi method and a telephone survey. However, we were unable to collect opinions from all the participants because of limited time and resources. Nevertheless, in contrast to other studies that separately compared elitist and public opinions, this study analyzed opinions 
of both groups by using the policy Delphi method and conducting a telephonic survey, thereby obtaining results that were more easily comparable.

\section{REFERENCES}

[1] Balarajan, Y., S. Selvaraj, and S. V. Subramanian 2011. India: Towards universal health coverage for health care and equity in India. Lancet, 377, 505-515

[2] Chen, L., W. Yip, M. C. Chang, H. S. Lin, S. D. Lee, Y. L. Chiu, and Y. H. Lin 2007. The effects of Taiwan's national health Insurance on access and health status of the elderly. Health Economics, 16(3), 223-242.

[3] Cheng, P. W. H. and T. M. Chu 2007. Health care insurance in Taiwan. Asian Studies Review, 33(3), 303-317.

[4] Cuyler, A. J. and A. Wagstaff 1993. Equity and equality in health and health care. Journal of Health Economics, 12(4), 431-457.

[5] Da Costa, M., M. Ferreira, V. Litlhakanyane, and B. Childs 2008. Universal health insurance-A global perspective. HASA Annals, 35-40.

[6] Faden, R., and S. Shebaya 2010. Public Health Ethics. In The Stanford Encyclopedia of Philosophy (Summer 2010 Edition), ed. Edward N. Zalta, URL $=<$ http://plato.stanford.edu/archives/sum2010/entries/publichealth-ethics/>.

[7] Gwatkin, D. R. 2001. The need for equity-oriented health sector reforms. International Journal of Epidemiology, 30, 720-723.

[8] Handler, A., M. Issel, and B. Turnock 2001. A conceptual framework to measure performance of the public health system, American Journal of Public Health. 91(8), 1235-1239.

[9] Hsiao, W. 2006. The Cost and Benefits of Taiwan's National Health Insurance System- An Evaluation Based on International Framework and Standard, DOH92-NH-1001, A Research Project Commissioned by Bureau of National Health Insurance.

[10] Koch, Jeffrey W. 1998. Political rhetoric and political persuasion: The changing Structure of Citizens' Preferences on Health Insurance during Policy Debate. Public Opinion Quarterly, 62(2), 209-229.

[11] Kreng, V. B. and C. T. Yang 2011. The equality of resource allocation in health care under the National Health Insurance System in Taiwan. Health Policy, 100, 203-210.

[12] Kreng, V. B. and Chi-Tien Yang 2011. The equality of resource allocation in health care under the national health insurance system in Taiwan. Health Policy, 100(2-3), 203-210.

[13] Lee, Sang-Yi, Nam Kyu Suh, and Jung-Kook Song 2009. Determinants of public satisfaction with the National Health Insurance in South Korea. International Journal of Health Planning and Management, 24(2), 131-146.

[14] Lloyd, J. ,\& S. Wait (2006). Integrated Care: A Guide for Policymakers. London: Alliance for Health and the Future.

[15] Lu, J. F. and W. C. Hsiao 2003. Does universal health insurance make health care unaffordable? Lessons from Taiwan. Health Affairs, 22(3), 77-88.

[16] Lu, J. F. Rachel and T. L. Chiang 2011. Evolution of Taiwan's health care system. Health Economics, Policy and Law, 6(1), 85-107.

[17] Maluka, S. O., A.-K. Hurtig, M. S. Sebastián, E. Shayo, J. Byskov, and P. Kamuzora 2010. Decentralization and health care prioritization process in Tanzania: From national rhetoric to local reality. International Journal of Health Planning and Management, 26(2), 102-120.

[18] OECD 2010a. OECD Health Policy Studies: Improving Value in Health Care: Measuring Quality. Paris: OECD.

[19] OECD 2010b. OECD Health Policy Studies: Value for Money in Health Spending. Paris: OECD.

[20] OECD 2010c. Health Care Systems: Efficiency and Policy Settings. Paris: OECD.

[21] Pauline, K.-M. 2010. Use of healthcare access models to inform the patient protection and affordable care act. Policy, Politics, \& Nursing Practice Policy, 11(4), 286-293.

[22] Robert Wood Johnson Foundation 2007. Public Opinion Strategies, "Public Perceptions of the State Children's Health Insurance Program Survey." Kaiser Network, The Henry J. Kaiser Family Foundation, August 2007.

[23] Robert Wood Johnson Foundation 2009. Changes in Health Care Financing \& Organization (HCFO) issue brief Public Perspectives on Health Delivery System Reforms.

[24] Schlesinger, M., and T. Lee 1993. Is health care different? popular support of federal health and social policies. Journal of Health Politics, Policy and Law, 18, 555-621.

[25] Soroka, Stuart N. 2011. Public Perceptions and Media Coverage of the Canadian Healthcare System: A Synthesis. A Report to the Canadian Health Services, Research Foundation. Ottawa: CHSRF.

[26] Soroka, Stuart N., Antonia Maioni, and Pierre Martin 2013. What moves public opinion on health care? Individual experiences, system performance, and media framing. Journal of Health Politics, Policy and Law, 38(5), 893-920. 
[27] Tsai, W.-C., P.-T. Kung, C.-L. Yaung, Y.-H. Li, and S.-C. Lin 2006. Accessibility to and satisfaction with healthcare by rural area residents. Taiwan Journal of Public Health, 25(5), 394-404.

[28] WHO 2010. Health Systems Financing: The Path to Universal Coverage. Geneva: World Health Organization.

[29] Wu, T., A. Majeed, and K. N. Kuo 2010. An overview of the healthcare system in Taiwan. London Journal of Primary Care, 3, 115-119. 